\title{
INHERENT SAFETY ANALYSIS OF THE KALIMER UNDER A LOFA WITH A REDUCED PRIMARY PUMP HALVING TIME
}

\author{
W. P. CHANG*, Y. M. KWON, H. Y. JEONG, S. D. SUK, and Y. B. LEE \\ Korea Atomic Energy Research Institute \\ 150 Dukjin, Yuseong, Daejeon, 305-353, Korea \\ "Corresponding author. E-mail : wpchang@kaeri.re.kr \\ Received September 30, 2009 \\ Accepted for Publication November 10, 2010
}

The 600 MWe, pool-type, sodium-cooled, metallic fuel loaded KALIMER-600 (Korea Advanced LiquId MEtal Reactor, $600 \mathrm{MWe}$ ) has been conceptually designed with an emphasis on safety by self-regulating (inherent/intrinsic) negative reactivity feedback in the core. Its inherent safety under the ATWS (Anticipated Transient Without Scram) events was demonstrated in an earlier study. Initiating events of an HCDA (Hypothetical Core Disruptive Accident), however, also need to be analyzed for assessment of the margins in the current design. In this study, a hypothetical triple-fault accident, ULOF (Unprotected Loss Of Flow) with a reduced pump halving time, is investigated as an initiator of a core disruptive accident. A ULOF with insufficient primary pump inertia may cause core sodium boiling due to a power-to-flow mismatch. If the positive sodium reactivity resulting from this boiling is not compensated for by other intrinsic negative reactivity feedbacks, the resulting core power burst would challenge the fuel integrity.

The present study focuses on determination of the limit of the pump inertia for assuring inherent reactivity feedback and behavior of the core after sodium boiling as well. Transient analyses are performed with the safety analysis code SSC-K, which now incorporates a new sodium boiling model. The results show that a halving time of more than $6.0 \mathrm{~s}$ does not allow sodium boiling even with very conservative assumptions. Boiling takes place for a halving time of $1.8 \mathrm{~s}$, and its behavior can be predicted reasonably by the SSC-K

KEYWORDS : ULOF, Pump Halving Time, Sodium Boiling, Reactivity, KALIMER, SSC-K

\section{INTRODUCTION}

The Korea Atomic Energy Research Institute (KAERI) has been pursuing a conceptual design of the KALIMER-600 (Korea Advanced LiquId MEtal Reactor, $600 \mathrm{MWe}$ ), a prototypic demonstration reactor for a commercial LMR (Liquid Metal Reactor) (Hahn, 2004). The KALIMER-600 is a liquid metal sodium-cooled fast reactor with an electricity output of $600 \mathrm{MWe}$ and it uses U-TRU-10\%Zr metal fuel. It has four design objectives: energy sustainability, enhanced safety, competitive economics, and proliferation resistance. In terms of safety, its design primarily pursues accident prevention, by relying on self-regulating (inherent/intrinsic) core characteristics and passive decay heat removal. A new core design concept is under development in an effort to enhance its nonproliferation resistance.

The EBR-II tests (Planchon, 1987) for ULOF (Unprotected Loss Of Flow) and ULOHS(Unprotected Loss of Heat Sink) demonstrated that the sodium-cooled, metallic fuel loaded LMR (Liquid Metal Reactor) could be shut down passively by the inherent negative reactivity feedback characteristics and that the fuel temperatures remained well below the melting point. Similar results were subsequently obtained in other large reactors following the EBR-II tests (Wade, 1997; Royl, 1992; Yokoo, 2001). The inherent safety of the KALIMER-600 design has already been demonstrated under ATWS (Anticipated Transients Without Scram) accidents, which were represented by UTOP (Unprotected Transient OverPower), ULOF (Unprotected Loss Of Flow), and ULOHS (Unprotected Loss of Heat Sink) (Kwon ${ }^{1}$, 2006). In addition to assessment of preventive safety, the initiating events of an HCDA (Hypothetical Core Disruptive Accident) also need to be analyzed in order to quantify its margins for assuring inherent safety and eventually for design improvement.

Upon this background, a hypothetical triple-fault accident, ULOF with a reduced primary pump halving time $\left(\tau_{1 / 2}\right)$, is analyzed as an initiator of a core disruptive accident. Even though it may be an accident with an extremely low probability and that lies far beyond the 
design basis, the margins between the design conditions and the physical safety limits would be of concern owing to the uncertainty incorporated in the design as well as in the analysis methodology. This uncertainty is believed to exist in such factors as the pump coast-down rate, the thermo-physical properties of the materials, and the reactivity feedback coefficients.

Three conditions are assumed to take place simultaneously in the triple-fault initiator. The first fault is a failure of the normal power supply for the primary coolant pumps. The offsite power supply for the primary pumps is not a safety-grade system, and thus a loss of flow event is probable. A failure to scram is the second fault, and the last is a loss of the designed primary pump coast-down. Despite having very low probability, a loss of a normal pump coast-down could occur in the event of a severe earthquake. In a loss of flow accident, the power-to-flow ratio is a key parameter that determines the consequences of the accident. A power-to-flow mismatch due to an insufficient pump halving time could lead to sodium boiling during the incident. If sodium boiling were to occur in the core, either positive sodium reactivity feedback would be traded off by other inherent negative reactivity mechanisms, or the reactivity would diverge. Such reactivity divergence would likely give rise to a sufficient core power excursion for the fuel temperature to reach the fuel melting point. In this respect, a number of parametric sensitivity calculations are carried out in this study to determine the margin of the pump halving time against sodium boiling.

Mechanical centrifugal pumps are used in the primary coolant circulation system in the KALIMER-600 design. The set primary pump halving time, which is defined as a time required for the nominal flow to be reduced to half its value, is $10.0 \mathrm{~s}$. This value is comparable to other designs. For example, the value about $6.0 \mathrm{~s}$ was used for MONJU or the demonstration FBR (Yamada, 2004 ), 8.0 $\mathrm{s}$ in a U.S. - Europe joint analysis of large scale FBRs (Yokoo, 2001), and $10.0 \mathrm{~s}$ for EFR (Darrington, 1993). It should be noted that an excessively long halving time elevates the possibility of cold shock to the IHX tube plate, because cold coolant may flow into the IHX during design basis events (Yokoo, 2001).

As part of the process of developing the KALIMER600 design, the safety analysis code, SSC-K, is continuously being evolved to extend its applicable range. It is now capable of calculating sodium boiling transients until fuel melting begins via a new sodium boiling model. It is also thereby able to provide the conditions required for a molten fuel motion analysis, which are necessary to assess the consequences after the failure of prevention mechanisms.

The main objectives of this study are to investigate the pump halving time that will ensure inherent safety of the KALIMER-600 under the triple-fault scenario, and how the transient develops if its inherent safety is not preserved. To this end, an overview of the KALIMER600 conceptual design is introduced first, followed by a brief description of the SSC-K. After presenting the analysis results, the findings of the present study are summarized in the final section and directions for coming studies are discussed.

\section{OVERVIEW OF THE KALIMER-600 CONCEPTUAL DESIGN}

An overview of the KALIMER-600 plant is given in Fig. 1. Its representative systems consist of one primary heat transport system (PHTS), two intermediate heat transport systems (IHTS), a steam generation system (SGS), two decay heat removal systems (DHX), and other connected systems. The reactor building adopts a seismic base isolation system to enhance structural safety as well as economics. The reactor building is separated from both the fuel handling-storage building and the turbine generator building.

The plant design life of the KALIMER-600 has been set at 60 years, based on a compromise between longer component lifetime and high thermal efficiency. The metallic fuel operates at a lower temperature than oxide fuel by reducing energy storage with enhanced heat conduction performance. The core is designed with a single enriched and radially homogeneous scheme, as seen in Fig. 2. There is no blanket assembly and the core conversion ratio is designed to be approximately unity in order to minimize excessive plutonium production for enhancement of the proliferation resistance. One of the benign features is that it has an extremely low burn-up reactivity swing, such that no substantial control rod movement is necessary to compensate for the fuel burn-up during the entire operation period.

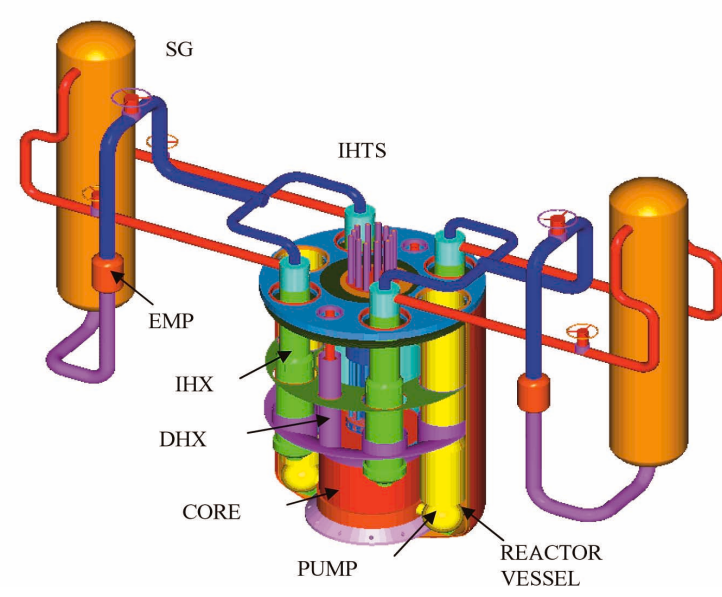

Fig. 1. Schematic of KALIMER-600 System 
As seen in Fig. 2, the ultimate shutdown system (USS) is located at the center of the core, and it drops into the core with neither an external control signal nor an actuating power but by a self-actuated Curie point electromagnet in the case of a reactor emergency. There are no upper or lower axial blankets surrounding the core. Each driver fuel assembly consists of 271 rods within a duct. A fuel pin is made of a sealed HT-9M tube containing the metal fuel slug in a column. HT9M is also used as structural material of the core. Its low irradiation swelling characteristics permits adequate nuclear performance in such a physically small core. Table 1 summarizes the major design parameters of the KALIMER-600 (Kwon $\left.{ }^{2}, 2006\right)$.

The PHTS is filled with sodium to a level below the reactor head, with a free surface exposed to the cover gas space. The sodium volume of the PHTS is designed such that the reactor core remains covered in the event of a vessel leak or rupture. In the normal primary flow path,

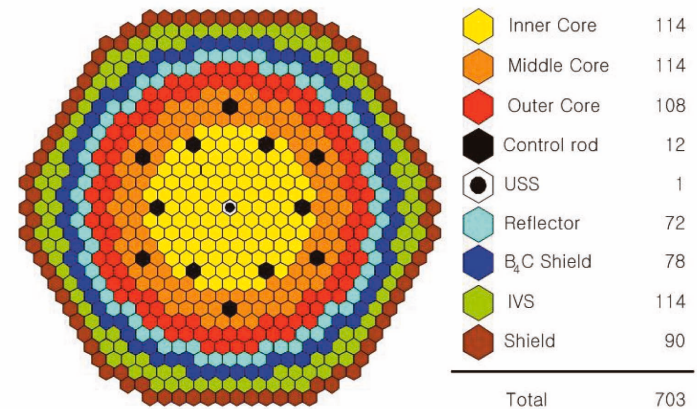

Fig. 2. KALIMER-600 Core Configuration

sodium coolant passing over the core is sent to the hot pool, and the sodium in the hot pool enters the IHX (Intermediate Heat Exchanger) to be cooled. The cooled

Table 1. Major Design Parameters of KALIMER-600

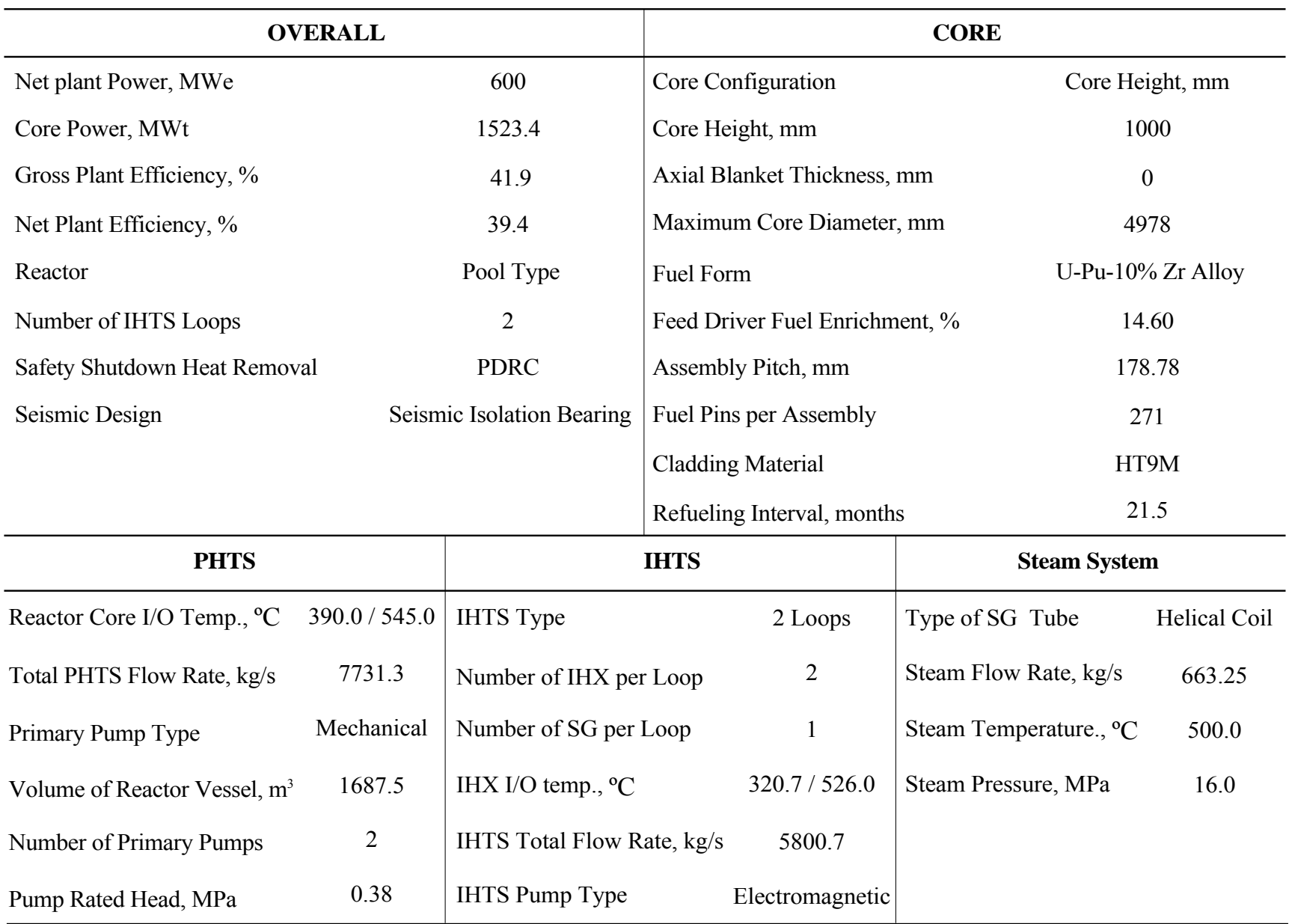

*BOEC : Beginning Of Equilibrium Cycle

*End Of Equilibrium Cycle 
sodium flowing out of the IHX then enters the cold pool to be forcibly circulated to the sodium distribution space at the core inlet by the primary centrifugal pumps. The SG (Steam Generator) is a once-through type with helical tubes and it generates superheated steam.

When the normal heat transfer path is not available, the core decay heat is removed either by the non-safety related IRACS (Intermediate Reactor Auxiliary Cooling System) or the safety related PDRC (Passive Decay heat Removal Circuit) system, which are schematically illustrated in Fig. 3. The PDRC system is comprised of two independent loops, in each of which a sodium-sodium decay heat exchanger (DHX), a sodium-air heat exchanger (AHX), and the associated interconnecting pipe system are installed. The heat removal capacity depends on the temperature of the overflowing reactor coolant through the reactor baffle. The containment vessel is a cylindrical structure surrounding the reactor vessel. The annular space between two vessels is filled with argon gas to prevent an air-sodium reaction during a sodium leakage accident from the reactor vessel.

\section{GENERAL DESCRIPTION OF THE SSC-K}

The SSC-K development began with the basis of the physical models in the SSC-L (Guppy, 1983), which had originally been developed at Brookhaven National Laboratory (BNL) to analyze a loop-type liquid metal reactor (LMR) system. Even though the SSC-L code had been substantially generalized and featured sophisticated

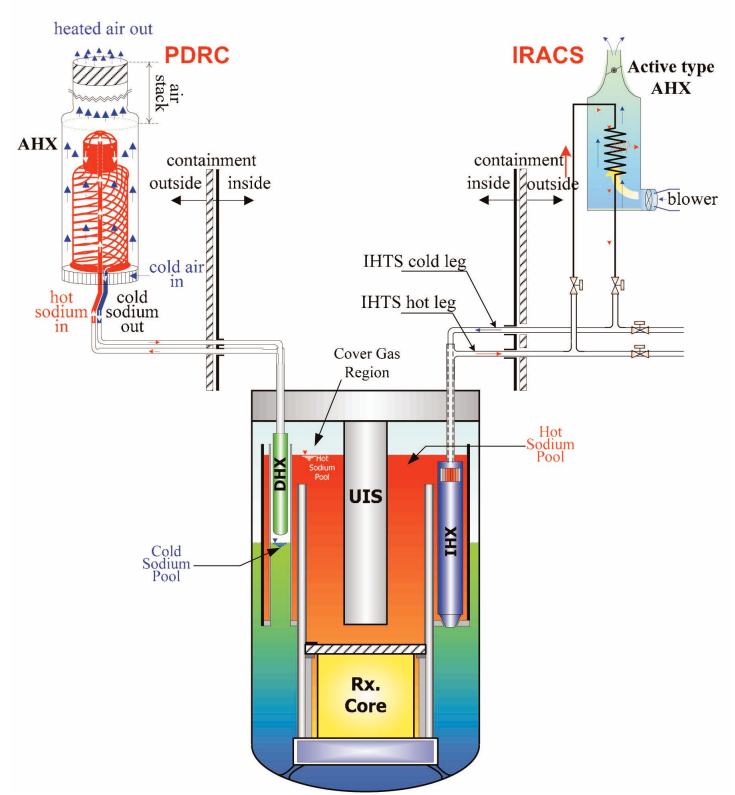

Fig. 3. Schematic of KALIMER-600 RHRS models for LMR simulations, some models had to be modified or added for adaptation to the KALIMER- 600 specific design. These models were those primarily concerned with the metallic-fueled core, the pool-type PHTS, multi-dimensional hot pool, sodium boiling, and the PDRC. In addition to model modifications, some existing theories were also rewritten. (Chang, 2002)

The SSC-K represents a reactor core with multiple coolant channels, each of which employs a one-dimensional thermal-hydraulics model to simulate the power and flow distributions within a core. The pump model in the SSC$\mathrm{K}$ can accommodate any centrifugal pump characteristics with a generalized homologous curve. A PDRC model is linked to it, and all other necessary component models are installed. The power generation is calculated by using both the neutron point kinetics model and the decay heat table provided by the code user. The axial profile of the core power generation is specified by the user input. Any power deposited in the cladding, coolant, or structural material is assumed to be distributed uniformly in the radial direction. The modeling capability of the reactivity feedback effects has been confirmed through code-tocode comparison analyses $\left(\mathrm{Kwon}^{3}, 2002 ; \mathrm{Kwon}^{4}, 2005\right)$ with the SAS4A/ SASSYS-1 (Cahalan, 1994). The SAS4A/SASSYS-1 model calculations were verified by good agreement for the reactivity balance with in-pile experiments in the Fast Flux Test Facility (FFTF), which had nearly an identical core restraint system as that of the KALIMER-600 (Wigeland, 1987; Hill, 1988).

The applicable range of the code is extended to allow computation of the void reactivity feedback induced by core sodium boiling. It is now capable of handling a wide range of transients, including those of normal operation, shutdown heat removal, hypothetical ATWS events, and sodium boiling. The SSC-K is continuously being developed to maintain its role as a reliable systems analysis code in the KALIMER-600 design.

\subsection{Reactivity Models}

The reactivity feedback models in the SSC-K account for the effects due to Doppler, sodium density/void, fuel axial expansion, core radial expansion, and control rod driveline expansion. Table 2 presents these reactivity worths, including the control rod system and USS (Ultimate Shutdown System) for the design. All the reactivity coefficients other than those for the sodium density are calculated with the DIF3D computer code, which uses 9 neutron energy groups with a trigonal-Z mesh system (Derstine, 1984). The PERT-K (Kim, 1998), meanwhile, generates the spatial reactivity coefficients for the sodium density based on a perturbation theory.

\subsubsection{Doppler Effect}

The fuel temperature (Doppler) coefficients due to the Doppler effect are evaluated for sodium-flooded/voided 
cases. The local Doppler coefficient data generated by the DIF3D are regressed to a correlation varying on the basis of $1 / \mathrm{T}^{1.05}$ for the sodium flooded case. It becomes less negative in the sodium-voided case and varies with $1 / \mathrm{T}^{1.08}$ due to neutron spectrum hardening. The fuel temperature coefficients do not show any substantial change with the fuel burn-up progress. Doppler feedback is the fastest acting feedback mechanism. The fuel temperature instantly responds to the core power level and is a nearly instantaneous indicator of a power excursion.

\subsubsection{Sodium Density/Void Worth}

Positive sodium void worth is found especially for a large, sodium-cooled, metallic-fueled core due to neutron spectrum hardening. Its effect sometimes outweighs all other negative reactivity feedback effects, and could lead to core damage. The total sodium void worths quoted in Table 2 assume voiding in all the active high-powered

Table 2. Reactivity Worths

\begin{tabular}{|c|c|c|}
\hline & BOEC & $\underline{\mathrm{EOEC}}$ \\
\hline \multicolumn{3}{|c|}{ Fuel Temperature (Doppler) Coefficient (d rho/ dT) } \\
\hline Sodium Flooded & $-0.00736 \mathrm{~T}^{-1.05}$ & $-0.00708 \mathrm{~T}^{-1.05}$ \\
\hline Sodium Voided & $-0.00636 \mathrm{~T}^{-1.08}$ & $-0.00618 \mathrm{~T}^{-1.08}$ \\
\hline \multicolumn{3}{|c|}{ Sodium Void Effect (pcm) } \\
\hline Inner Core & 1438 & 1481 \\
\hline Middle Core & 1063 & 1104 \\
\hline Outer Core & 149 & 190 \\
\hline Total & 2618 & 2659 \\
\hline \multicolumn{3}{|c|}{ Core Raidal Expansion Coefficient } \\
\hline$(\mathrm{dk} / \mathrm{k}) /(\mathrm{R} / \mathrm{dR})(\mathrm{pcm} / \%)$ & -447 & -447 \\
\hline $\mathrm{dk} / \mathrm{dT}(\mathrm{x} 10-6)(1 / \mathrm{K})$ & -6.4775 & 6.4722 \\
\hline \multicolumn{3}{|c|}{ Fuel and Clad Axial Expansion Coefficients } \\
\hline$(\mathrm{dk} / \mathrm{k}) /(\mathrm{dH} / \mathrm{H})(\mathrm{pcm} / \%)$ & -79.2 & -77.3 \\
\hline \multicolumn{3}{|l|}{ Control Rods (pcm) } \\
\hline Primary Rod & 3103 & 3061 \\
\hline Secondary Rod & 1093 & 1123 \\
\hline Total & 4428 & 4421 \\
\hline USS (pcm) & 500 & 561 \\
\hline Total Beta-effective & 0.00355 & 0.00352 \\
\hline
\end{tabular}

fuel assemblies. The sodium worth increases with fuel burn-up.

\subsubsection{Radial Expansion Effect}

Core radial expansion due to a rise of coolant temperature is one of the dominant negative reactivity mechanisms in a metallic-fueled reactor. The core assemblies are held both by their nosepieces on the grid plates and by load pads near the top of the assemblies, which are surrounded by core restraint rings attached to the core barrel, as seen in Fig. 4. A radial core expansion, which leads to negative reactivity feedback, basically results from a core dilation due to thermal expansion of both the grid plate below the core and the two sets above the core load pads (ACLP). The negative reactivity feedback is further enhanced by outward bowing of the core periphery assemblies due to radial temperature gradients and restraints. Fig. 4 schematically represents these bowing effects.

A simple calculation model for radial reactivity feedback is used in the SSC-K, as no detailed model to account for the bowing effect is available at present. The radial growth of the core is determined by the expansion of the lower grid support structure and the duct walls at the above the core load pads, respectively. The expansion of the lower grid support structure is assumed to be proportional to the rise of the subassembly inlet temperature above its initial steady-state value. The expansion at the location of the above the core load pads is assumed to be proportional to the change in the average structure temperature at this location. The radial expansion reactivity

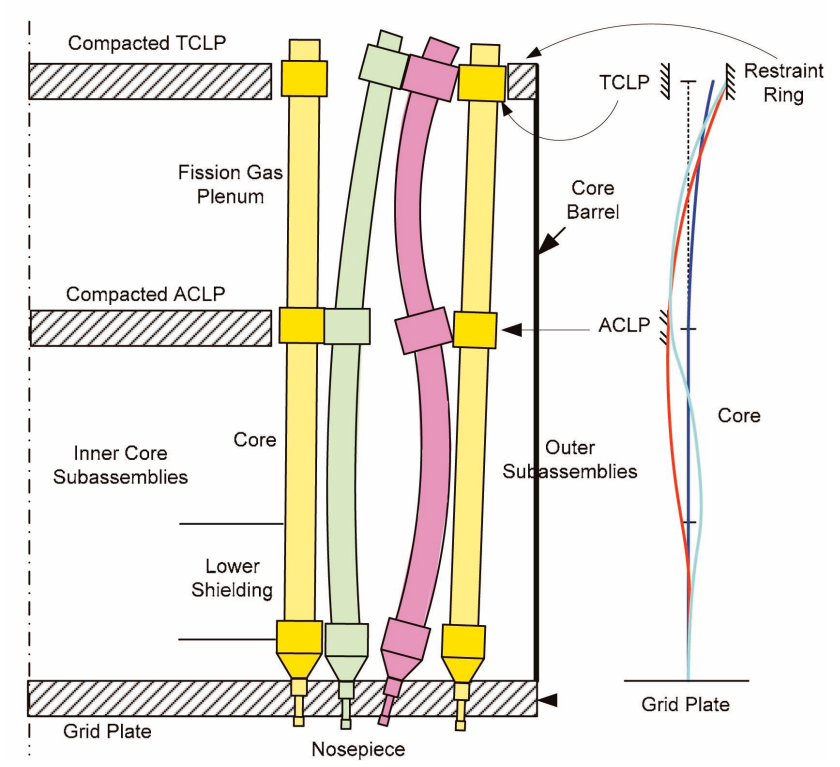

Fig. 4. Radial Reactivity Feedback Mechanisms 
feedback is calculated from the following equation:

$$
\begin{aligned}
& \Delta k_{\text {radial }}(t)=C_{\text {radial }} \\
& {\left[\Delta T_{\text {in }}+\frac{D_{C M}\left(\Delta T_{S L P}-\Delta T_{\text {in }}\right)}{D_{A C L P}}\right] }
\end{aligned}
$$

where

$$
\begin{array}{ll}
\mathrm{t}= & \text { time, second } \\
\mathrm{t}_{1} & =\text { time at the end of first main time step, second } \\
\mathrm{T}_{\text {in }}(\mathrm{t})= & \text { coolant inlet temperature, } \mathrm{K} \\
\mathrm{C}_{\text {radial }}= & \text { coefficient, } \$ / \mathrm{K} \\
\Delta \mathrm{T}_{\text {in }}= & \mathrm{T}_{\text {in }}(\mathrm{t})-\mathrm{T}_{\text {in }}\left(\mathrm{t}_{1}\right), \mathrm{K} \\
\mathrm{D}_{\mathrm{CM}}= & \text { distance from nozzle support point to core } \\
& \text { mid-plane, } \mathrm{m} \\
\mathrm{D}_{\mathrm{ACLP}}= & \text { distance from nozzle support point to above } \\
& \text { core load pad, } \mathrm{m} \\
= & \text { structure temperature (outer structural radial } \\
& \text { node }) \text { in channel i at the axial node corresp- } \\
\mathrm{T}_{\mathrm{SLP}}(\mathrm{i}, \mathrm{t}) & \text { onding to the above core load pad } \\
= & \mathrm{T}_{\mathrm{SLP}}(\mathrm{i}, \mathrm{t}) \text { averaged over the channel } \mathrm{i} \\
\mathrm{T}_{\mathrm{SLP}}(\mathrm{t}) \quad & \mathrm{T}_{\mathrm{SLP}}(\mathrm{t})-\mathrm{T}_{\mathrm{SLP}}\left(\mathrm{t}_{1}\right), \mathrm{K}
\end{array}
$$

The radial expansion model was given in the original SSC-L, and a similar model was adopted in the SAS4A/SASSYS-1. Hence, the SSC-K only models two contributions for the radial reactivity feedback, i.e. the linear expansions of the grid plate and the ACLP. They are weighted by 0.35 and 0.65 , respectively, depending on the core inlet and outlet coolant temperatures (Kwon ${ }^{4}$, 2005). This results in a conservative radial reactivity calculation for the inherent safety of the design, because the bowing effect, which contributes to negative reactivity feedback, is not incorporated. Radial thermal expansion of the core support structure is a relatively slow feedback mechanism.

\subsubsection{Fuel Axial Expansion}

Metallic fuel is known to expand significantly with burn-up progress. Its expansion reaches as high as $4 \%$ with $1.9 \sim 5.3 \%$ burn-up (Kwon $\left.{ }^{4}, 2005\right)$. Radial fuel slug expansion is retained within a pin, and the fuel bundle lattice remains unchanged, and thus does not affect the reactivity. Axial fuel expansion, however, lowers the fuel effective density as it elongates the active core. Therefore, the SSC-K uses a reactivity coefficient based on a unit mass in a similar manner as that used for sodium reactivity, i.e.,

$$
\rho^{A X}=e \sum_{J K} C_{J K} N_{J K}^{*}
$$

where $C_{J K}$ denotes the reactivity coefficient per mass at the $\mathrm{J}$ node in the $\mathrm{K}$-coolant channel and it is a user input. $N^{*}{ }_{J K}$ indicates the effective mass that has disappeared due to the density change at the JK node, while $e$ is an overall uncertainty factor accounting for the axial expansion and the reactivity effect by expanded fuel.

Axial expansion increases the probability that neutrons will escape from the core, causing significant negative reactivity feedback as the fuel temperature increases. On the other hand, geometric change affects the neutron capture rate at the same time. Nevertheless, the net effect is negative reactivity feedback for the fuel temperature increase, and it is a fast feedback mechanism.

\subsubsection{CRDL (Control Rod Drive Line)}

Since control rod drivelines are submerged in the hot pool sodium, they expand and push the control rods further down into the active zone. Meanwhile, part of this driveline expansion has the same effect as the part of this driveline being taken out from the core as the thermally expanding vessel walls lower the core support. The resulting effective reactivity feedback, therefore, relies on the net result of the two expansions. It may be classified as a slow feedback mechanism, because the reactor vessel wall along with the core support structure responds slowly to the core coolant temperature during transients. The SSC-K preserves the same model that was linked to the reference code, the SSC-L for application to the looptype CRBR (Clinch River Breeder Reactor). In addition, the CRDL design has not yet been completed. Its reactivity feedback effect, for this reason, is not taken into consideration in the present analysis to allow for a conservative assumption.

\subsection{Sodium Boiling Model}

Even though the KALIMER design may not allow sodium boiling to take place under any circumstances of design basis accidents, sodium boiling is still anticipated under certain HCDA initiating events. For an assessment of the HCDA consequences, it is necessary to understand the transient developments that lead to a core disruption. In this regard, a sodium boiling model has been developed based on a multi-bubble slug ejection model similar to that used in the SAS2A (Dunn, 1974; Chang, 2001). The model theoretically describes sodium boiling behavior well, but its implementation in the SSC-K is not practical as in some cases it is very sensitive to certain parameters provided by the user input. Furthermore, instability has been observed when bubbles elongate beyond a certain length. Thus, an alternative model has been pursued. The model developed by the USNRC (Khatib-Rahbar, 1982) provided a useful theoretical base for the present development of the SSC-K version. This model has been linked to the SSC-L and applied to the analysis of a lossof-flow transient for the CRBR, as well as in the analysis of natural convection in ORNL rod bundle experiments. By adopting averaged concepts in the boiling channel, the model employs a more practical approach for the 
descriptions of the governing equations. The compatibility as well as eligibility was proven to be feasible for interfacing with the SSC-K (Chang, 2006). The theory is summarized in this section.

The conservation of the mass, momentum, and energy equations for a constant channel flow area can be written as:

$\underline{\text { Mass }}$

$$
\frac{\partial \rho}{\partial t}+\frac{1}{A} \frac{\partial W}{\partial X}=0
$$

Momentum

$$
\begin{aligned}
\frac{1}{A} \frac{\partial W}{\partial t} & +\frac{1}{A^{2}} \frac{\partial}{\partial X}\left(\frac{W^{2}}{\rho^{*}}\right) \\
& +\frac{f}{2 \rho D_{e} A^{2}} W|W|+\rho g+\frac{\partial P}{\partial X}=0
\end{aligned}
$$

Energy

$$
\frac{\partial}{\partial t}(\rho h)+\frac{1}{A} \frac{\partial}{\partial X}(W h)=Q
$$

$A, W$, and $h$ represent the flow area, channel mass flow rate, and enthalpy, respectively, in the channel. The nonconservative form of equation (4), combining the mass and energy equations, yields:

$$
\rho \frac{\partial h}{\partial t}+\frac{W}{A} \frac{\partial h}{\partial X}=Q
$$

A set of conservation equations, (3), (4), (6), with a total channel length $(L)$ and spatial increment $\left(\Delta X_{j}\right)$ can be transformed into numerical form as:

$$
\begin{gathered}
A L \frac{d \hat{\rho}}{d t}=W_{\text {in }}-W_{\text {out }} \\
\frac{L}{A} \frac{d \hat{W}}{d t}=\left(P_{\text {in }}-P_{\text {out }}\right)-\left(\frac{1}{\rho_{o}^{*}}-\frac{1}{\rho_{i}}\right) \frac{\hat{W}^{2}}{A^{2}} \\
-g \sum_{j=1}^{N-1}\left\langle\rho_{j}\right\rangle \Delta X_{j}-\left|\frac{\hat{W}}{A}\right| \frac{\hat{W}}{A} \sum_{j=1}^{N-1} \frac{\phi_{j} f_{j} \Delta X_{j}}{2 \rho_{f} D e} \\
-\frac{1}{2}\left[\frac{K_{\text {in }}}{\rho_{i}}+\frac{K_{o} \phi_{o}}{\rho_{o}}\right]\left|\frac{\hat{W}}{A}\right| \frac{\hat{W}}{A} \\
\left\langle\rho_{j}\right\rangle V \frac{d h_{j+1}}{d t}=W\left(h_{j}-h_{j+1}\right)+Q
\end{gathered}
$$

The channel is further divided into pre- and post-boiling regions, as illustrated in Fig. 5. Channel average density $(\hat{\rho})$, channel average flow $(\hat{W})$, and in Equation (7) are defined, respectively, as:

$$
\hat{\rho}=\int_{0}^{L} \rho d X ; \quad \frac{1}{L} \sum_{j=1}^{N-1}\left\langle\rho_{j}\right\rangle \Delta X_{j}
$$

$$
\hat{W}=\frac{1}{L} \int_{0}^{L} W(X) d X ; \quad \frac{1}{L}\left(L_{b} W_{\text {in }}+\left(1-L_{b}\right) W_{\text {out }}\right)
$$

$$
W= \begin{cases}W_{\text {in }} & X<L_{b} \\ W_{\text {out }} & X \geq L_{b}\end{cases}
$$

Note that the average channel flow $(\hat{W})$ is approximated by weighting $W_{\text {in }}$ and $W_{\text {out }}$ with the pre-boiling length $\left(L_{b}\right)$. Here, $\left\langle\rho_{j}\right\rangle$ indicates the node volume average density. The sodium temperature is evaluated as a function of the enthalpy only, i.e. $T_{j}=T\left(h_{j}\right)$, while the sodium density is expressed as $\rho_{j}=\rho\left(T_{j}\right)$.

The solution scheme begins with finding $\hat{W}^{n+1}$ in Eq. (8) by using both $\left(P_{\text {in }}-P_{\text {out }}\right)^{n+1}$, given as boundary conditions, and the other closure parameters evaluated at the previous time-step. $(n+1)$ denotes the variables at an advanced time step, while $\mathrm{n}$ gives those at the previous time step. Calculation of the enthalpy $\left(h_{j+1}^{n+1}\right)$ in Eq. (9) is then followed based on $W_{i n}^{n}$ or $W_{o u t}^{n}$ and $\left\langle\rho_{j}^{n}\right\rangle$. Boiling junctions are identified by comparing each junction enthalpy $\left(h_{j+1}^{n+1}\right)$ with the saturation enthalpy corresponding

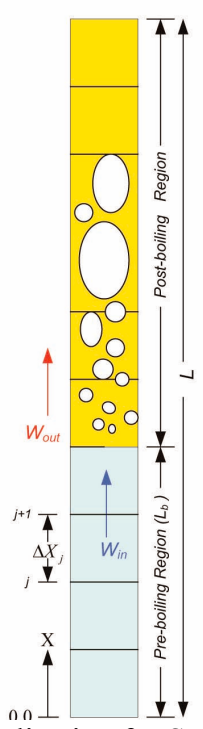

Fig. 5. Channel Nodalization for Sodium Boiling Model 
to the single channel average pressure $\left(\left(P_{\text {in }}+P_{\text {out }}\right) / 2\right)$ calculated by the SSC-K in the coolant channel. $L_{b}^{n+1}$, which is the axial height of the junction immediately below the boiling junction, is then determined. Once $\left\langle\rho_{j}^{n+1}\right\rangle$ is derived based on the new enthalpy, $\hat{\rho}^{n+1}$ is obtained from Eq. (10) as well. Finally, $W_{i n}^{n+1}$ and $W_{\text {out }}^{n+1}$ are found from Eq. (7) by combining the relation in Eq. (11).

\section{ANALYSIS OF ULOF WITH A REDUCED PRIMARY PUMP HALVING TIME}

\subsection{SSC-K Modeling for KALIMER-600}

Figure 6 displays a nodalization for the simulation of the KALIMER-600 using the SSC-K. Both the primary and intermediate heat transport circuits are modeled, and the core is represented by seven channels with a respective height of $3.77 \mathrm{~m}$. Each active core channel (Middle Driver, Inner Driver, Outer Driver, and Hot Driver) is divided into a total of 14 segments, among which 10 segments are assigned to the fuel slug, and two out of the four remaining segments are assigned to the lower shielding plug and upper gas plenum, respectively. In contrast, both the Control and Reflector channels are represented with 10 equally spaced segments while the shield and IVS (In-vessel Storage) channel are represented with only one. Since the BOP (Balance Of Plant) system does not impact the safety performance, it is simplified as a boundary condition in terms of the feed water and steam conditions.

In the analysis, the ULOF transient is initiated by trips of both primary pumps at 0.0 second for the fullpower condition. Figure 7 depicts the power generation profile in the hot channel, given as an input, and the

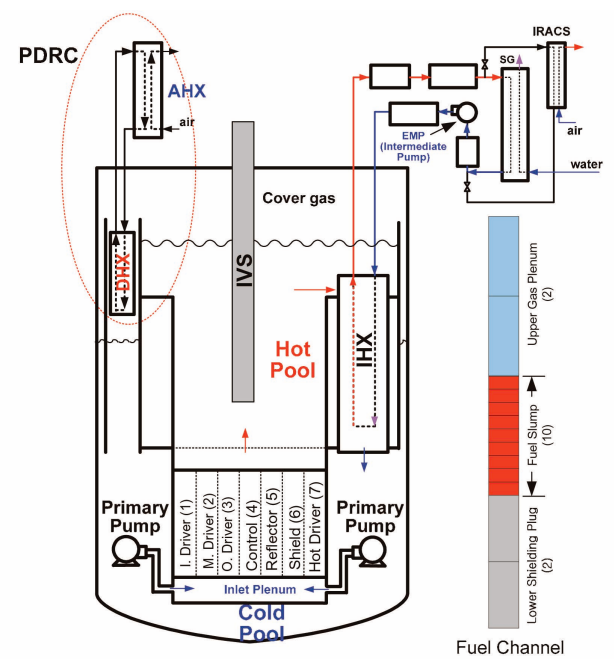

Fig. 6. Schematic of SSC-K Model for KALIMER-600 Plant highest power occurs at the position of $1.595 \mathrm{~m}$ (Node \#7) above the core bottom. The shape itself remains unchanged during the entire transient. The magnitude, however, depends on the reactivity feedback. The pumps then go through a coast-down, while the electromagnetic pumps in the intermediate loops are assumed to operate throughout the entire transient. Four IHXs are available to remove the core heat, and, therefore, the heat generated in the core is removed through the normal heat removal path.

\subsection{Analysis Results}

Shown in Fig. 8 are the calculation results for the transient power and flow variations with the pump halving times. All the responses to the halving times other than $\tau_{1 / 2}=1.8 \mathrm{~s}$ exhibit benign behaviors. For $\tau_{1 / 2}=1.8 \mathrm{~s}$, however, the power excursion indicates that sodium boiling takes place, and the channel flow direction is reversed instantly

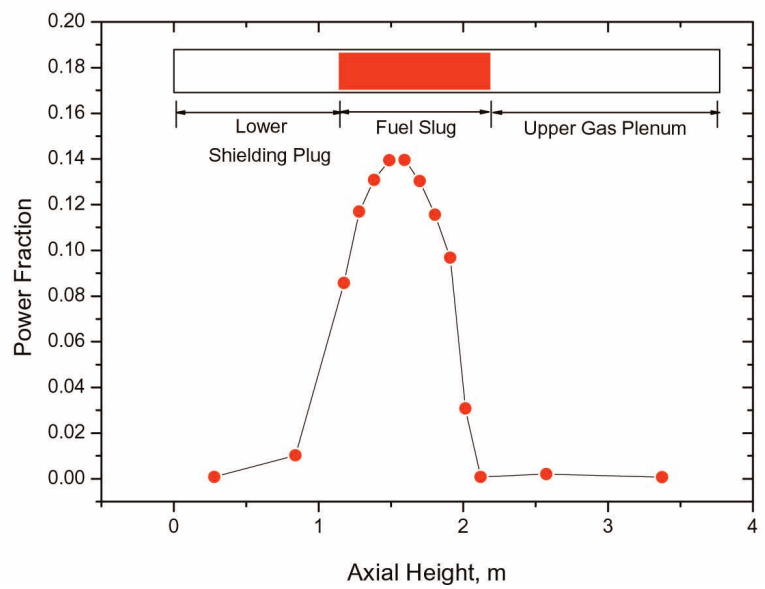

Fig. 7. Axial Power Generation Profile for the Hot Channel

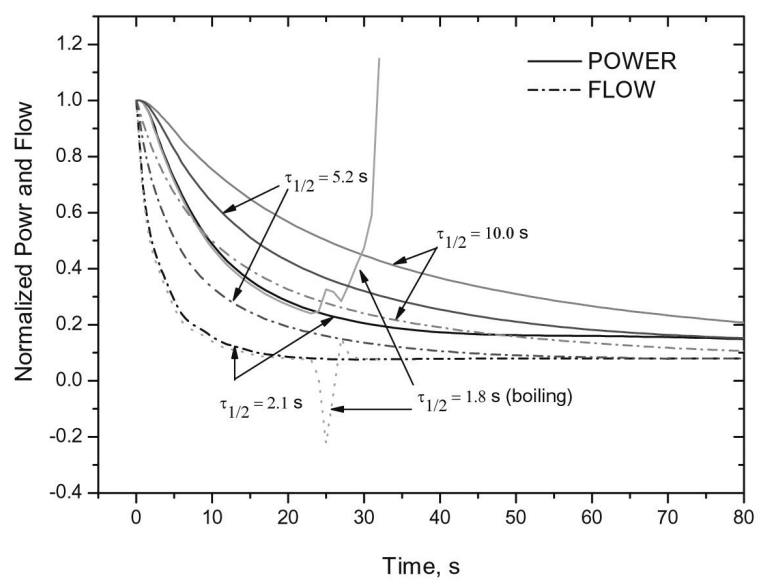

Fig. 8. Power and Flow Transients with Pump Halving Times 
at the boiling and then recovered, apparently arising from an abrupt flow resistance increase due to a core channel voiding. Figure 9 presents the results of the net reactivity feedback calculated by the SSC-K. A divergence of the reactivity feedback from sodium boiling is noticed. After the slumping reactivity initially reaches the lowest point, it tends to climb again as soon as the positive sodium reactivity encounters other negative reactivity contributions. A similar trend to the net reactivity feedback is found in the radial reactivity response shown in Fig. 10. The early power increase caused by the power-to-flow mismatch raises the fuel, coolant, and core outlet temperatures, as seen in Figs. 11, 12, and 13. The rapid temperature increases, in turn, induce a large inherent negative reactivity feedback, which restrains a further increase of the power; the culminating temperatures then begin to fall rapidly. The core outlet coolant temperature should meet the safety

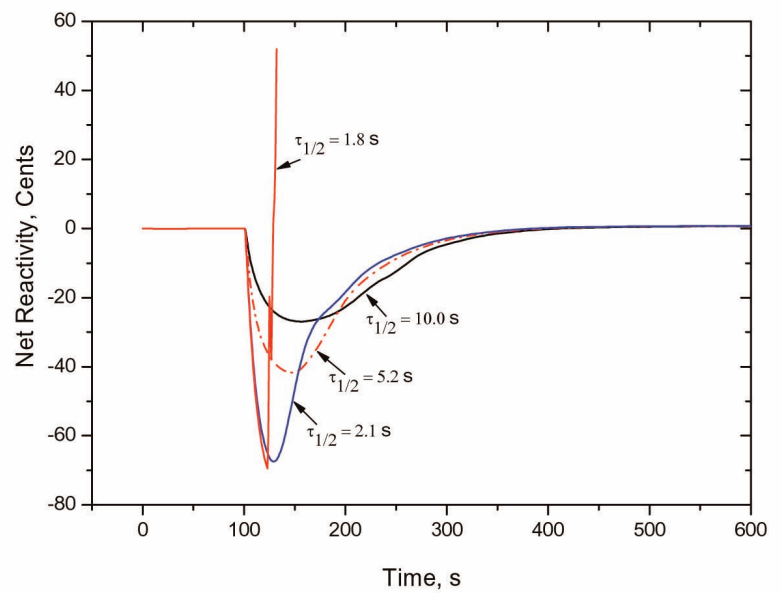

Fig. 9. Net Reactivity Feedbacks with Pump Halving Times

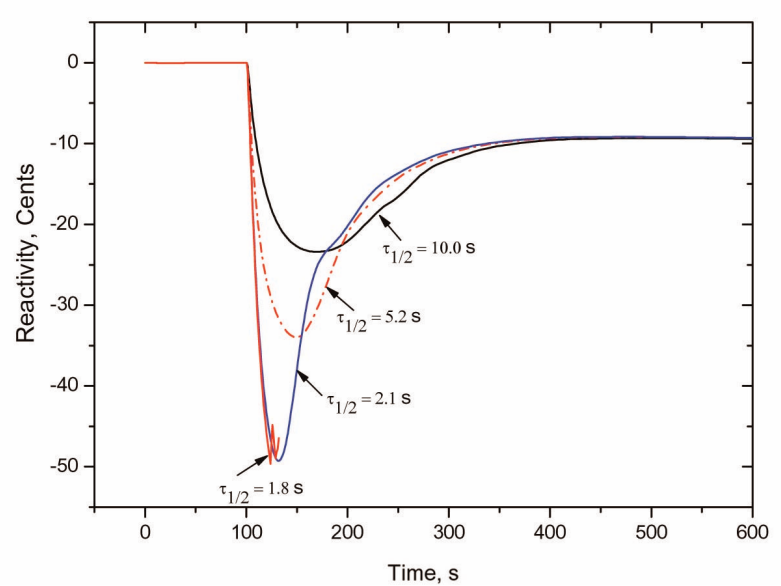

Fig. 10. Radial Reactivity Feedbacks with Pump Halving Times

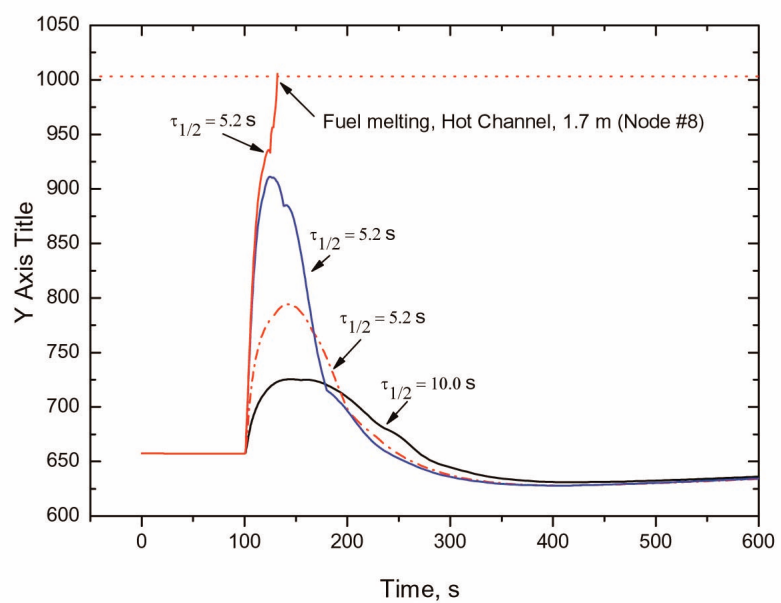

Fig. 11. Maximum Fuel Temperatures with Pump Halving Times

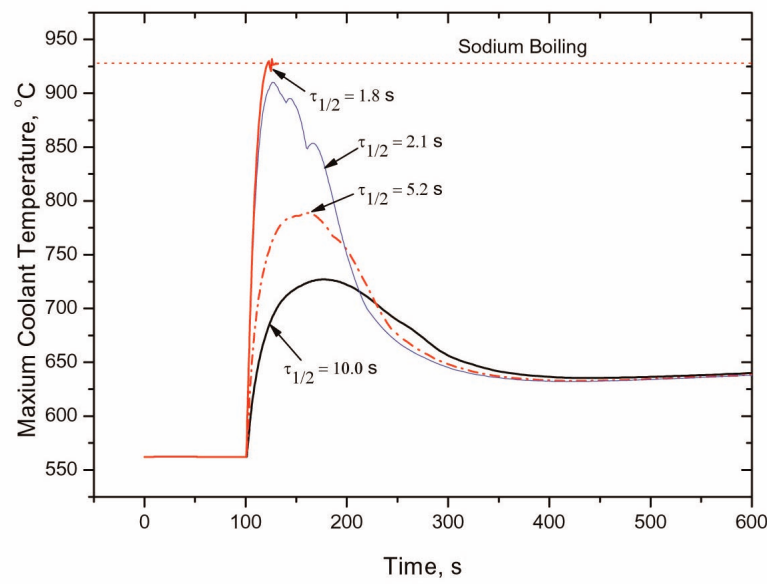

Fig. 12. Maximum Sodium Temperatures in the Core

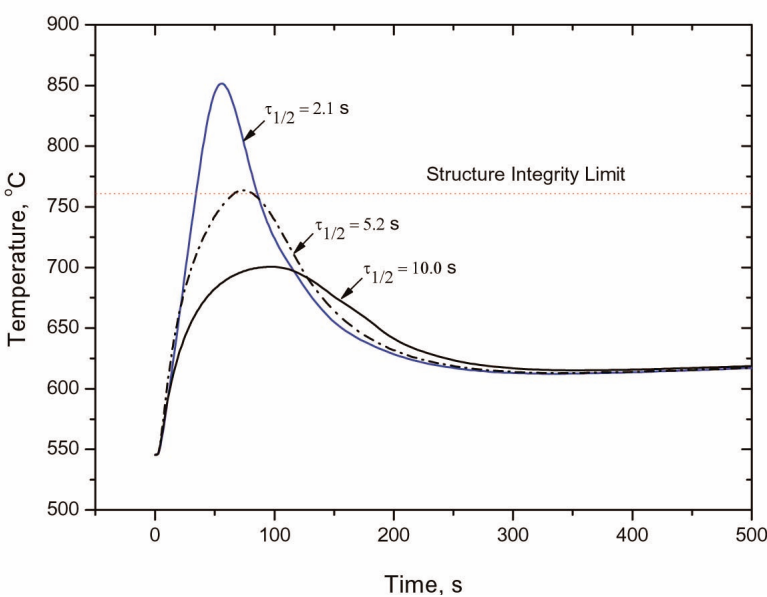

Fig. 13. Core Outlet Sodium Temperatures 
limit based on ASME level D for a short-term period $\left(760{ }^{\circ} \mathrm{C}\right)$ so as to maintain the primary boundary vessel integrity. Fig. 13 presents the results of the core outlet temperatures for the examined halving times. A halving time of around $\tau_{1 / 2}=5.2 \mathrm{~s}$ may be the limit, while there still exists a margin for sodium boiling of approximately $135^{\circ} \mathrm{C}$. (Fig. 12) Figures 9, 10, 11, 12 include steady runs for 100 seconds conducted to demonstrate stable initial conditions for the transients, while the other figures are drawn neglecting the steady runs.

As $\tau_{1 / 2}$ is reduced to $1.8 \mathrm{~s}$, sodium boiling indeed takes place. Figure 14 shows the results of the reactivity feedbacks. After the onset of sodium boiling, the positive reactivity does not show an immediate burst. Rather, its growth reveals a somewhat mild trend for a few seconds, because the initial boiling incepted near the upper gas plenum appears to enhance neutron leakage. The reactivity increase thereafter is dramatically enhanced as the void spreads out to the high power region. The

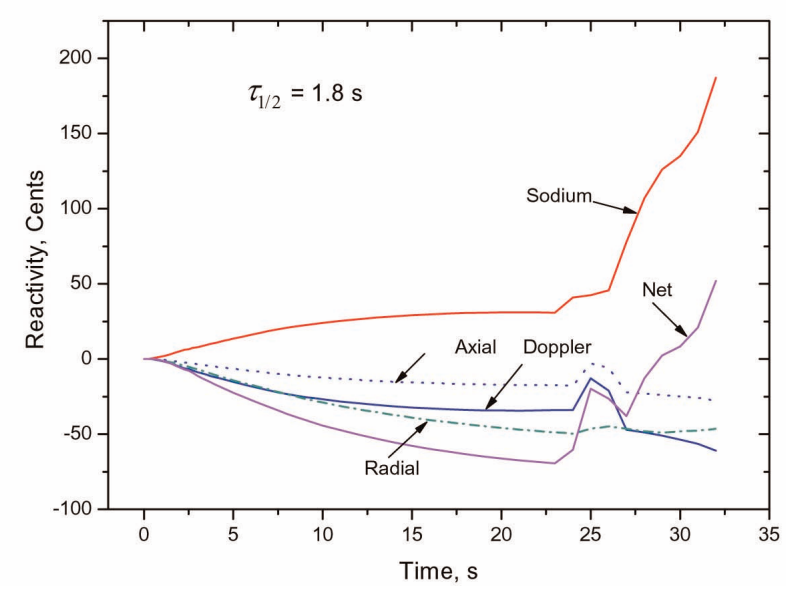

Fig. 14. Reactivity Feedbacks for $\tau_{1 / 2}=1.8 \mathrm{~s}$

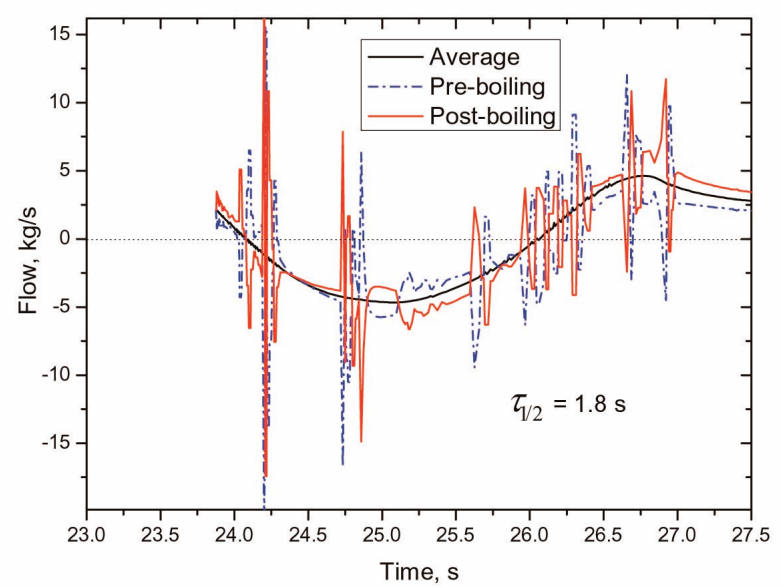

Fig. 15. Flows in the Boiling Model for $\tau_{1 / 2}=1.8 \mathrm{~s}$ sodium reactivity rapidly increases to as high as $\$ 2$ at the fuel melting time within several seconds, while the net reactivity reaches approximately $50 \not$. Voiding is distributed in the region between node \#7 $(1.6 \mathrm{~m})$ and \#12 $(2.12 \mathrm{~m})$, where most of the high heat generation nodes are located. Boiling first begins in the Inner Driver ( Channel \#2), including the hot channel (Channel \#7), followed by the Middle Driver (Channel \#1) and Outer Drive (Channel \#3) in the order of their power-to-flow ratio. Figure 15 reveals that the calculated flow is very sensitive to voids. The voided nodes are directly influenced by a flow perturbation. The discontinuities of the voids observed in nodes \#10 (1.91m), $12(2.12 \mathrm{~m})$, and $13(2.23 \mathrm{~m})$ in Fig. 16 reflect such cases. As cooler sodium flows backward into the voided channels from the hot pool due to a flow reversal, boiling, especially in the upper region, is suppressed. The positive sodium reactivity rapidly increases as all the central nodes are covered by a void after about $28 \mathrm{~s}$, as can be seen by

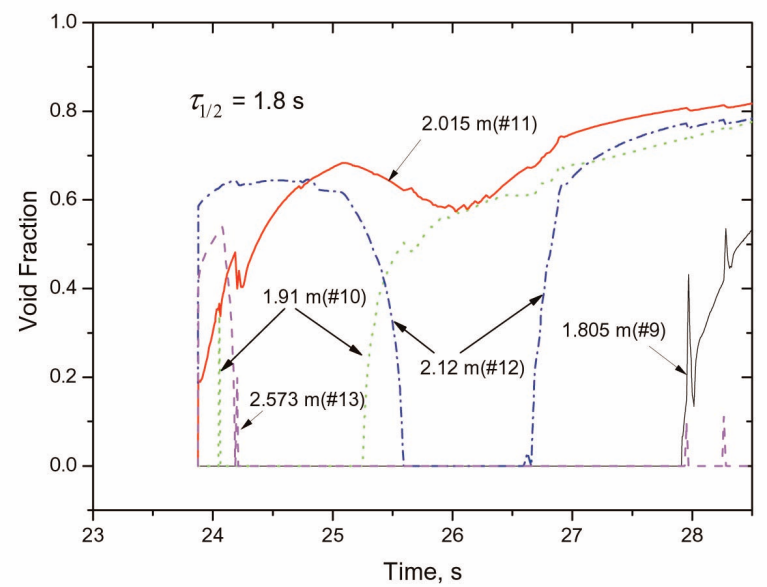

Fig. 16. Void Fraction Variations with Axial Positions for $\tau_{1 / 2}=1.8 \mathrm{~s}$

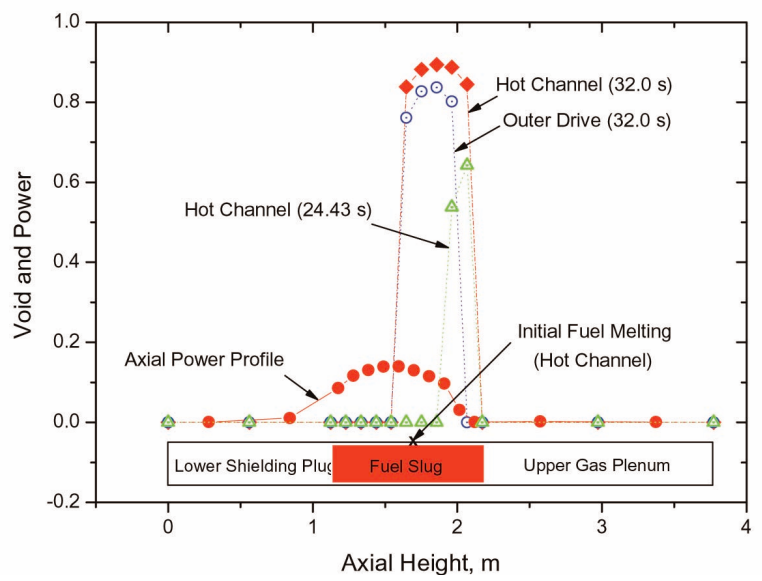

Fig. 17. Channel Void Fraction Profiles for $\tau_{1 / 2}=1.8 \mathrm{~s}$ 
comparing Fig. 16 with Fig. 17.

The comparison study showed that each reactivity contribution in the present model did not deviate significantly from the SAS4A/SASSYS-1 predictions. The net reactivity difference in the comparison for UTOP did not exceed $2 \not$. $\left(\mathrm{Kwon}^{3}, 2002\right)$ For the radial reactivity, the present model excludes bowing of the peripheral subassemblies, and thereby its contribution is presumably less negative than it should be. Moreover, the CRDL reactivity feedback, which leads to negative reactivity feedback, is also ignored. Therefore, it is apparent that sufficient conservatism was provided in the reactivity calculation for the analysis. Under all the circumstances, sodium boiling is excluded for $\tau_{1 / 2}=10.0 \mathrm{~s}$, even if the radial reactivity feedback is ignored (Fig. 18). Figure 18 shows that the coolant temperature for $\tau_{1 / 2}=10.0 \mathrm{~s}$ lies far below the eutectic formation temperature (approximately $1000{ }^{\circ} \mathrm{C}$ ) (Royl, 1992). As the cladding temperature is close to the coolant temperature, a significant cladding penetration rate resulting from eutectic formation is not likely to happen.

\section{CONCLUSION}

Using the system transient code SSC-K, a triple-fault accident, ULOF with a reduced primary pump halving time, has been analyzed with some conservative assumptions in order to quantify the margin associated with the designed pump halving time $\left(\tau_{1 / 2}\right)$ for the KALIMER-600 conceptual design. Sodium boiling calculations beyond the inherent safety limit have also been carried out to observe the sodium reactivity response and its physical development after appearance of a core void.

As a result, the primary pump halving time, $\tau_{1 / 2}=1.8 \mathrm{~s}$, is found to be the inherent safety limit, beyond which

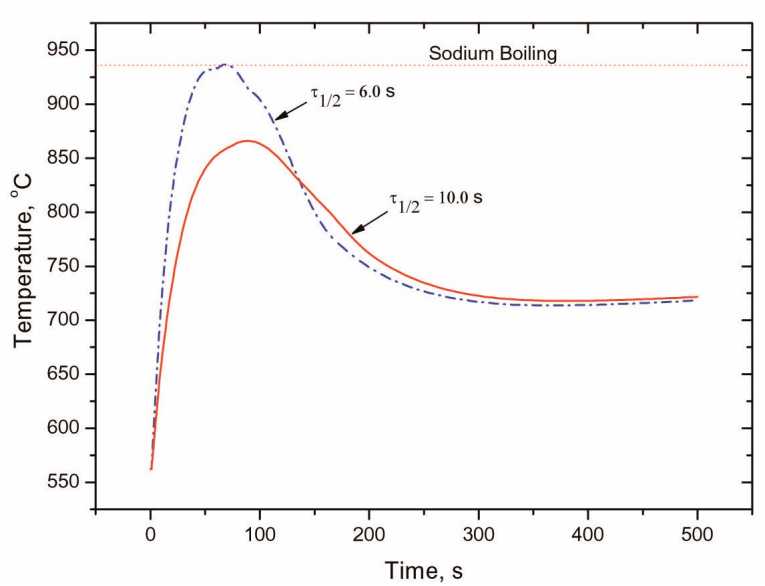

Fig. 18. Maximum Sodium Coolant Temperatures with no Radial Reactivity sodium boiling takes place. On the other hand, a halving time longer than $\tau_{1 / 2}=6.0 \mathrm{~s}$ could prevent core sodium boiling even when ignoring the radial reactivity feedback. No safety limit is violated with a pump halving time as short as $\tau_{1 / 2}=5.2 \mathrm{~s}$, and hence the present setting of $\tau_{1 / 2}=10.0$ $\mathrm{s}$ provides a conservative margin for sodium boiling or fuel melting. This study suggests a possibility that the present pump halving time can be further reduced by up to $\tau_{1 / 2}=6.0 \mathrm{~s}$ by reducing the uncertainties involved in both the design and the related safety analysis. The predictions by the sodium boiling model are considered physically reasonable.

It has been demonstrated that the reactivity feedback due to radial core expansion acts as a key passive safety feature. Radial expansion is a combined mechanism of the grid plate and load pad thermal expansions and subassembly bowing. The radial core expansion model in the SSC-K, however, is presently related only to the linear expansions of the grid plate and the ACLP. To supplement the model, a calculation model for core bowing reactivity feedback, which requires coupled complex calculations associated with neutronics, thermal-hydraulics, and mechanics, will be incorporated in the current simple model $\left(\mathrm{Kwon}^{5}, 2005\right)$. If this is successfully accomplished, the results will contribute to substantially reducing the uncertainty involved in analyses with the SSC-K.

The present sodium boiling model uses a channel average approach and assumes homogeneous sodium boiling. Although the model may be effective for low heat flux natural circulation scenarios such as in the case of a loss-of-flow transient, it would not be adequate for high heat flux forced flow situations. Therefore, ensuing study of this issue will follow together with the development of a molten fuel relocation model for the HCDA analysis in the next stage.

\section{ACKNOWLEDGEMENTS}

This work was performed under the Long-Term Nuclear R \& D Programs sponsored by the Korea Ministry of Science and Technology.

\section{NOMENCLATURE}

$P_{\text {in }}$ and $P_{\text {out }}=$ Inlet and outlet boundary pressures.

$\phi_{j}, f_{j} \quad=$ Two-phase multiplier and single-phase wall friction factor at the junction $j$, respectively.

$$
\phi_{j}=\left(1+x_{j} \frac{v_{f g}}{v_{f}}\right) g\left(1+x_{j} \frac{\mu_{f g}}{\mu_{g}}\right)^{0.25}
$$

Here, $v, x_{i}$, and $\mu$ indicate specific volume, quality, and viscosity, respectively.

$D_{e} \quad=$ Hydraulic diameter

$K_{i n}, K_{o} \quad=$ Inlet and outlet form loss coefficients

$A_{i}, A_{o} \quad=$ Inlet and outlet channel flow areas 
$\phi_{o} \quad=$ Two-phase multiplier at the outlet

$$
\equiv\left(1+\frac{v_{f g}}{v_{f}} x_{o}^{1.5}\right)
$$

$x_{o} \quad=$ Outlet quality

$\rho_{i} \quad=$ Liquid density at the channel inlet

$\rho_{o} \quad=$ Liquid density at the channel exit

$\rho_{j} \quad=\left(1-\alpha_{j}\right) \rho_{f}+\alpha_{j} \rho_{g}$ : Two-phase junction density

$x_{j} \quad=\left(h_{j}-h_{f}\right) / h_{\mathrm{fg}}$ : Two-phase junction quality

$Q \quad=h_{c} A\left(T c-\left\langle T_{j}\right\rangle\right)$ : Total heat transfer from the cladding to coolant

$\left\langle T_{j}\right\rangle$ : Volume average temperature, $\left\langle T_{j}\right\rangle=\left(T_{j+1}+T_{j}\right) 2$

\section{REFERENCES}

[ 1 ] Hahn, D. et al., "KALIMER-600 preliminary conceptual design report," KAERI/TR-2784/2004

[2] Planchon, H.P., Sackett, J.I., Golden, G.H., and Sevy, R.H., "Implications of the EBR-II inherent safety demonstration test," Nucl. Eng. Des. 101, pp. 75-91

[ 3 ] Wade, D.C., Wigeland, R.A., and Hill, D.J., "The safety of the IFR," Progress in Nuclear Energy 31, pp. 63-82

[4] Royl, P.H. et al., "Performance of metal and oxide fuel cores during accidents in Large Liquid-Metal-Cooled reactors," Nucl. Technol. 97, pp. 198-210

[5] Yokoo T. and Ohta H., "ULOF and UTOP analyses of a large metal fuel FBR core using a detailed calculation system," J. Nucl. Science and Technology, 38, pp. 444-452

[6] Kwon, Y.M. et al. ${ }^{1}$, "Evaluation of inherent safety features of the KALIMER-600 design concept for Anticipated Transient Without Scram events," KAERI/TR-3163/2006

[7] Kwon, Y.M. ${ }^{2}$, "KALIMER-600 design data for the plant safety analysis," KALIMER/SA221-WR-05, Rev.0/2006

[ 8 ] Guppy, J.G., "Super System Code (SSC, Rev.0) An advanced thermo-hydraulic simulation code for transient in LMFBRs," NUREG/CR-3169

[9] Chang, W.P. et al., "Model development for analysis of the Korea Advanced Liquid Metal Reactor," Nucl. Eng. and Design, 217, pp. 63-80

[10] Kwon, Y.M. et al. , "Comparative analysis of an unprotected overpower transient in the KALIMER design using the SSC-K and the SAS4A/SASSYS-1 computer codes,"

\section{KAERI/TR-2202/2002}

[11] Kwon, Y.M. et al. ${ }^{4}$, "Comparative analysis for evaluating passive safety design features of the KALIMER-150," Trans. Ame. Nucl. Soc., 92, pp. 440-441

[12] Cahalan, J.E. et al., "Advanced LMR safety analysis capabilities in the SASSYS-1 and SAS4A computer codes," Proceedings of the Int. Topical Meeting on Advanced Reactor Safety, Pittsburg, Pennsylvania, ANS, pp. 17-21, 1994

[13] Derstine, K.L., "DIF3D : A code to solve one-, two-, and three-dimensional finite-difference diffusion theory problems," ANL-82-64

[14] Kim, T.K. et al., "Development of a perturbation code for hexagonal core," Proceedings of '98 KNS Autumn Meeting, Korea Nuclear Society, 1998

[15] Kwon, Y.M. et $\mathrm{al}^{5}$, "A plan for the development of the spatial kinetics and the detailed reactivity model for a fast reactor," KAERI/TR-3071/2005

[16] Dunn, F.E. et al., "The SAS2A LMFBR accident-analysis computer code," ANL-8183

[17] Chang, W.P. et al., "Sodium voiding analysis in KALIMER," $9^{T H}$ International Conference On Nuclear Engineering, Nice, France, April 2001

[18] Khatib-Rahbar, Mohsen et al., "Modeling and analysis of low heat flux natural convection sodium boiling in LMFBRs," NUREG/CR-2006

[19] Chang, W.P. and Lee Y.B., "Development of a coolant analysis model for the sodium reactivity calculation in the KALIMER core," KAERI/TR-3212/2006

[20] Wigeland, R.A., "Effect of a detailed radial core expansion reactivity feedback model on ATWS calculations using SASSYS/SAS4A," Trans. Am. Nucl. Soc., 53, pp. 303-305

[21] Wigeland, R.A., "Comparison of the SASSYS/SAS4A radial core expansion reactivity feedback model and the empirical correlation for FFTF," Trans. Am. Nucl. Soc., 55, pp. 423-424

[22] Hill, D.J. and Wigeland, R.A., "Validation of the SASSYS core radial expansion reactivity feedback model," Trans. Am. Nucl. Soc., 56, pp. 380-381

[23] Darrington, T.M., "Non-Site-Specific Safety Report," EFR Associates, A0-00-0-258-A

[24] Yamada, F., Kitamura, K., "Realistic safety margin analysis of 'MONJU' based on plant performance measurements," $12^{T H}$ International Conference On Nuclear Engineering, Arlington, Virginia, USA, April 2004 